\title{
“Worldwide Network for Blood \& Marrow Transplantation (WBMT) special article, challenges facing emerging alternate donor registries"
}

\author{
Mahmoud Aljurf $^{1} \cdot$ Daniel Weisdorf ${ }^{2} \cdot$ Feras Alfraih $^{1} \cdot$ Jeff Szer $^{3}{ }^{3} \cdot$ Carlheinz Müller $^{4} \cdot$ Dennis $^{\text {Confer }}{ }^{5}$. \\ Shahrukh Hashmi ${ }^{1}$ • Nicolaus Kröger ${ }^{6}$ Bronwen E. Shaw ${ }^{7} \cdot$ Hildegard Greinix $^{8} \cdot$ Mohamed A. Kharfan-Dabaja $^{9}$. \\ Lydia Foeken $^{10}$ - Adriana Seber ${ }^{11}$. Syed Ahmed ${ }^{1}$. Areej El-Jawahri ${ }^{12}$. Moheeb Al-Awwami ${ }^{1}$ Yoshiko Atsuta $^{13}$. \\ Marcelo Pasquini ${ }^{7}$. Amr Hanbali ${ }^{1}$ - Hazzaa Alzahrani ${ }^{1}$ - Shinichiro Okamoto ${ }^{14}$ • Eliane Gluckman $^{15,16}$.

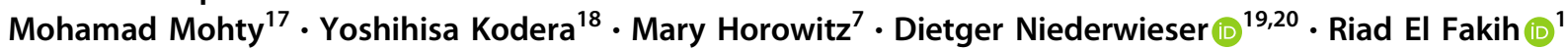

Received: 11 December 2018 / Revised: 16 January 2019 / Accepted: 17 January 2019 / Published online: 18 February 2019

(c) The Author(s) 2019. This article is published with open access

\begin{abstract}
Hematopoietic cell transplantation (HCT) activity is increasing at an unprecedented pace with $>50,000$ allogeneic transplants occurring annually worldwide. Establishing a functional HCT donor registry can be very challenging with respect to ethnicities, financial, technical, and geopolitical issues. Extensive planning steps are essential to overcome the expected challenges while establishing the registry, and to maintain its functionality. A few strategies can help move past those challenges and push the development of such registries forward. Authorities involved in HCT donor registry establishment will have to balance the advantages and costs of such a project and accommodate the emerging alternatives such as cord blood or related haploidentical transplants. Miscalculations and incomplete understanding of the various aspects of the process can have tremendous impact on the optimization of a HCT donor registry especially in developing countries. Herein we present some challenges in establishing such a registry and present potential solutions.
\end{abstract}

Feras Alfraih

falfraih@kfshrc.edu.sa

$\triangle$ Riad El Fakih

riadfakih@hotmail.com

1 Adult Hematology/HSCT, Oncology Centre, King Faisal Specialist Hospital \& Research Centre, Riyadh, Saudi Arabia

2 University of Minnesota, Minneapolis, MN, USA

3 Clinical Haematology at Peter MacCallum Cancer Centre and Royal Melbourne Hospital, VIC 3050, Australia

4 Zentrales Knochenmarkspender-Register ZKRD, Ulm, BW, Germany

5 Center for International Blood and Marrow Transplant Research, National Marrow Donor Program/Be The Match, Minneapolis, USA

6 University Hospital Hamburg, Hamburg, Germany

7 Center for International Blood and Marrow Transplant Research (CIBMTR), Medical College of Wisconsin, Milwaukee, WI, USA

8 Medical University of Graz, Division of Hematology, Graz, Austria 9ayo Clinic, Jacksonville, FL, USA

10 World Marrow Donor Association, Leiden, Netherlands

11 Hospital Samaritano de São Paulo, Sao Paulo, Brazil

12 Massachusetts General Hospital, Boston, MA, USA

13 Japanese Data Center for Hematopoietic Cell Transplantation, Nagoya, Aichi, Japan

14 Asia-Pacific Blood and Marrow Transplantation Group (APBMT), Tokyo, Japan

15 Eurocord Hôpital Saint-Louis and University Paris Diderot, Paris, France

16 Monacord Centre scientifique de Monaco, Monaco, France

17 Hopital Saint-Antoine, Sorbonne University, INSERM UMRs 839, Paris, France

18 Japan Marrow Donor Program (JMDP), Tokyo, Japan

19 Department of Hematology and Medical Oncology, University Hospital, Leipzig, Germany

20 Lithuanian University of Health Science, Kaunas, Lithuania 


\section{Introduction}

Hematopoietic cell transplantation (HCT) is a wellestablished curative therapy for certain types of cancers, blood disorders, genetic diseases, immunodeficiencies, and autoimmune conditions. The success of allogeneic HCT (allo-HCT) depends in large part on the degree of human leukocyte antigen (HLA) matching between recipient and donor. The ideal donor for allo-HCT is a matched sibling donor (MSD) but the overall chance of finding a MSD in each family is only $\sim 25-30 \%$ [1] in the western world. The first evidence of hematopoietic stem cell engraftment was reported in 1957 by E. Donnall Thomas [2], and the first successful syngeneic HCT was done in 1969 [3]. The first successful matched unrelated donor (MUD) transplant took place in 1973 [4] when a patient with inherited immunodeficiency received an allo-HCT from a donor identified as a match through a blood bank in Denmark. Using MUDs to perform allo-HCT has been life-saving opportunity for patients without a MSD. This was the driving force to develop unrelated donor registries around the globe. The UK started the world's first bone marrow donor registry, established by the Anthony Nolan Trust (ANT) in 1974 [5]. The number of allo-HCTs continues to increase worldwide, however many patients in need are unable to receive a transplant because a donor is not available for different reasons. The National Marrow Donor Program (NMDP) in the United States has > 19 million donors (https://bethema tchclinical.org) but the majority of them are Caucasian, and the chance of finding a donor for a patient from another ethnicity or race is low, partly because of the under representation of minorities and different ethnicities in these large registries, but also because of the differences in HLA haplotype frequencies. This highlights the importance of local registries because generally ethnic groups share unique common haplotypes [6-8] and thus the chance of finding a MUD becomes much higher using local registries. However, establishing a registry for a region or a country can be immensely challenging. This special article will summarize challenges faced by emerging registries at a country and regional level with special emphasis on alternate donor registries in developing countries.

\section{Challenges}

Cancer is one of the major causes of morbidity and mortality around the world; statistical models predict that in 2020 there will be 15 million new cancer cases, and that much of the cancer burden (mortality, incidence, and morbidity) will occur in the developing world [9]. Fig. 1 shows that cancer mortality will increase by $104 \%$ worldwide in 2020 , and that the mortality rate would be fivefold higher in

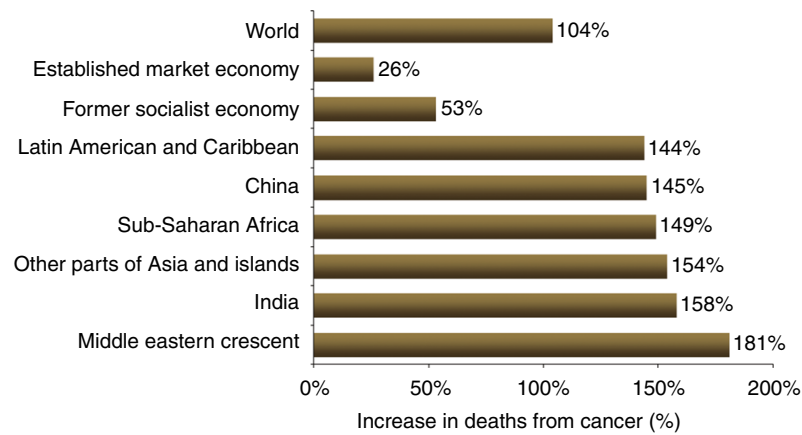

Fig. 1 Expected cancer mortality rates in 2020

the developing world $[10,11]$. This shift in disease burden is related to many factors including but not limited to poor access to advanced diagnostic and therapeutic modalities, research and epidemiologic data, cancer control, and prevention strategies $[12,13]$. This, combined with the expected rapid and large population growth in developing countries [14] and changing population pyramids is alarming. Fig. 2 shows that the majority of the expected population growth will occur in developing countries. Fig. 3 shows the large proportion of younger people in these countries, which will accelerate the rapid growth in these countries and increase the demand on medical needs as compared with developed world countries. Fig. 4 shows the worldwide location of unrelated donor registries and outlines the limited number of registries outside North America, Europe, and East Asia. A comparison of Figs. 2-4 reflects the disproportionately limited number of donor registries in the developing world where most of the future growth and demand will be. These facts highlight the importance of adopting policies to close the gap and increase regional donor registries to facilitate transplants in "increasing-demand" countries. A first step toward correcting this problem is to understand the challenges faced when establishing a donor registry in these countries.

1. Funding: maintaining a functional registry is expensive. Each step requires financial backup (donor recruitment, education events for the public, HLA typing (number of tested loci), ancillary tests (ABO, CMV, other infectious disease markers, etc.), laboratory maintenance, wages, donor collection facilities, software, etc.), plus the costs of maintaining contact with and communication with an increasing number of potential donors represent a significant financial burden for developing countries. This has led to the preferential and broad use of MUD HCT by high-income countries and rapid growth of related haploidentical transplantation as an alternative transplantation modality in lower income countries $[15,16]$. A recent report from the Worldwide Network for Blood \& Marrow Transplantation (WBMT) showed that MUD HCT is increasing worldwide with a preferential increase in high income countries 


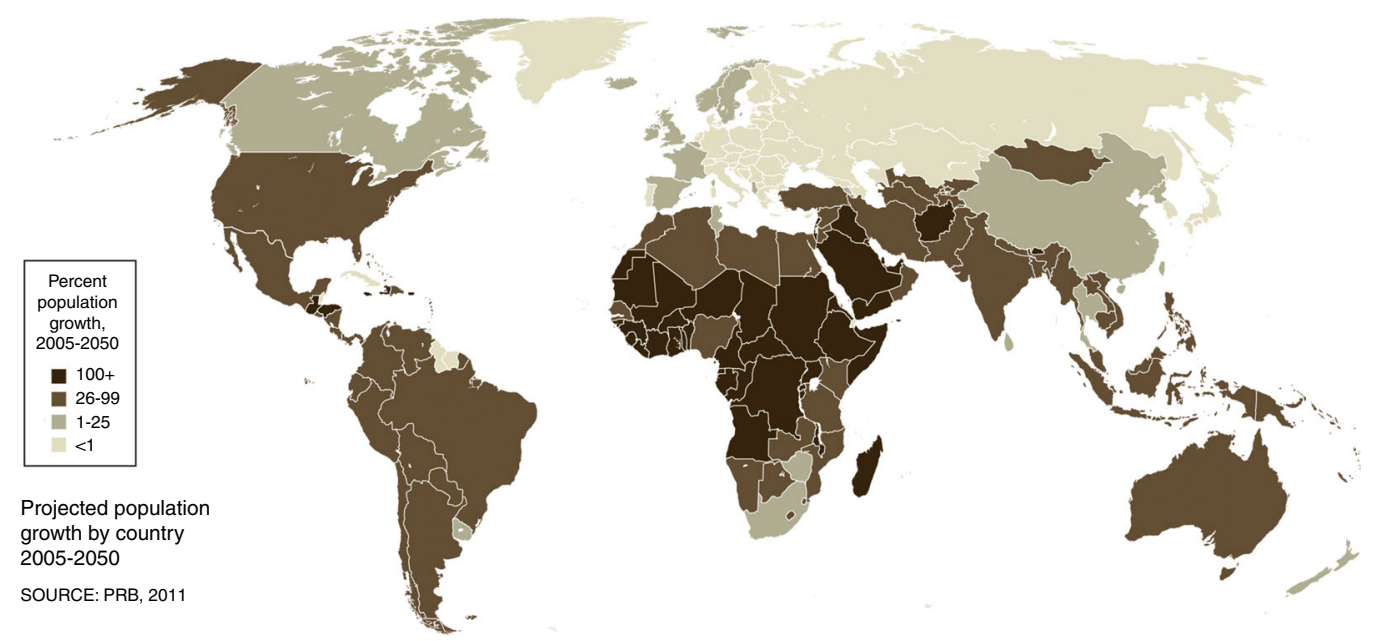

Fig. 2 Projected population growth by country 2005-2050

Fig. 3 Age distribution in developing versus developed countries

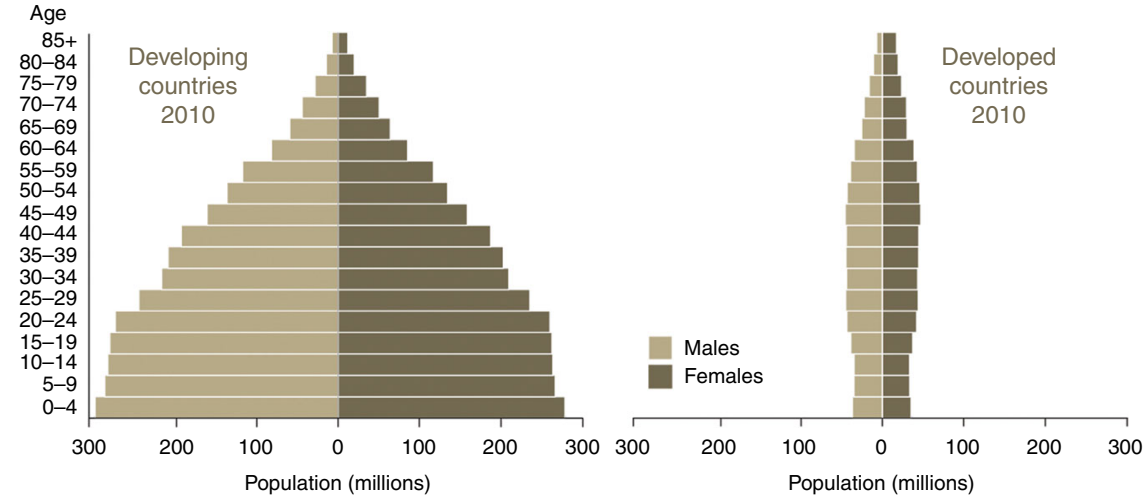

Fig. 4 Location of unrelated donor registries worldwide

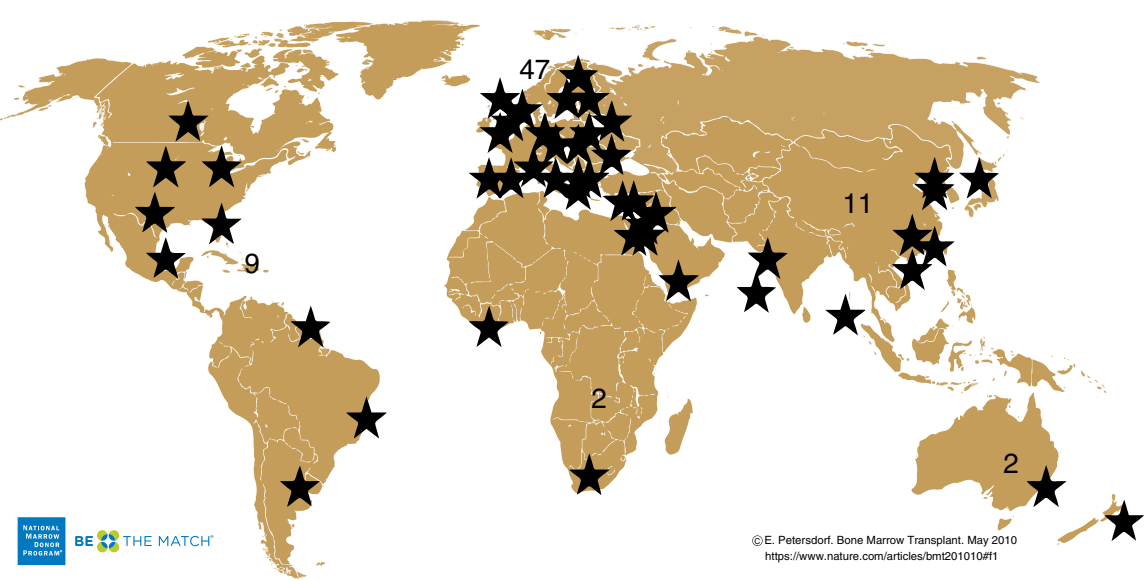

$(P=0.02)$, with a clear association between transplant rates and Gross National Income per/capita $(P<0.01)$ [17]. Funding of a new regional or country registry is a major financial burden particularly in the early phases of establishing the registry and before the registry is functional in providing alternate donor grafts. Two pathways are traditionally followed, government funding (full or partial) and charity, either from private companies or patient support organizations.

2. Donor issues: emerging registries aim to improve donor availability for the country/region with its unique HLA phenotype spectrum. The needed registry size will 
depend on multiple factors including target population size, homogeneity of the population, and haplotype frequency distribution. India, for example, has a large, nonhomogeneous population with $>300$ distinct ethnic groups and 438 languages. In India, there are five organizations listing donors for international recipients: BMST India as an intermediary of DKMS Registry (21,695 donors), Be The Cure Registry-Jeevan Foundation (6449 donors), Datri Blood Stem Cells Registry (367,561 donors), GeneBandhu (7,991 donors), and the Marrow Donor Registry India (MDRI) (35,768 donors). (Source: https://statistics.wmda. info). However, the chance of finding a MUD at 10/10 low resolution level is only $19 \%$, whereas the chances of finding a donor at high-resolution 10/10 level is even less [18]. Merging registries at the country level might offer greater efficiency. Mapping haplotype frequencies to regions in the country has allowed modeling future donor registry size [19]. Therefore, larger number of donors will be needed to be effective for patients in need of a transplant. Recruiting a large number of voluntary donors and minimizing donor attrition rates is difficult for multiple reasons, including lack of awareness, ethnic, religious, and other factors such as prevalence of infectious diseases in certain populations and BMI higher than 40 , which is a relative exclusion criterion for donation. A US study showed that individuals from the white population are $30 \%$ more likely to donate compared with other racial groups and that some minorities have more religious and cultural objections to donate and report less trust in stem cell transplantation [20]. Awareness campaigns and counseling are good opportunities to help overcome fears, myths, and doubts, and thus maximize recruitment, donor commitment, and minimize attrition. Educating the public regarding various conditions that can be cured by transplantation may engage more volunteers. Recruiting regular platelet and blood donors is helpful as these donors are usually motivated to donate and already familiar with the apheresis procedure. Reaching out to key influencers and public figures in the society, collaborating with schools and organizations, using vaccination campaigns strategies, new educational tools and platforms, as well as social media may help to diffuse the mission of the alternate donor registry and expand registry size.

3. Haplotype frequency: HLA genes are very polymorphic with more than 18,000 alleles (http://hla.alleles. org/alleles/index.html) [21]. HLA loci have tight linkage and this characteristic has made HLA haplotype frequencies a useful tool to study population genetics, migration patterns, anthropological characteristics, as well as to determine the optimal composition and needed size for an effective registry $[22,23]$. The mixing and ethnic diversity of a population increases the frequency of novel haplotypes and thus complicates the search for a compatible alternate donor. For instance, compared with the rest of the world, more than a third of HLA types within the Indian population are novel and unique [24]. On the other hand, in Saudi Arabia, a more homogeneous country, the chance of finding a $10 / 10$ MUD is projected to be $\sim 50 \%$ with a registry size of one million donors (Fig. 5) [25]. Another homogenous country is Japan where 8/8 HLA-matched donors are found for $96 \%$ of the patients [26]. In summary, the more heterogeneous the ethnic make-up of a country, the larger the registry size needed to ensure donor availability and registry cost-effectiveness. Computer programs to help estimating haplotype frequency are available to facilitate registry size planning [27]. Furthermore, HLA haplotype frequencies have a pivotal role for search algorithms designed to identify matching unrelated donors and are essential to estimate the probability of matching in a registry of a given size [19].

4. HLA typing: HLA typing by PCR testing was introduced by Mullis and Faloona in the 1980s [28]. Several PCR techniques are currently available, including DNA amplification with sequence-specific primers (SSP) [29], single-strand conformation polymorphism (SSCP) [30], sequence-specific oligonucleotide probes (SSO) [31], sequence-based typing (SBT) [32], DNA chip technology [33], and next-generation sequencing (NGS) [34-36]. These techniques offer better accuracy and are more reliable than serologic methods, and definitely help to standardize HLA-typing methods [37]. However, rapid progress in NGS technology has led to revolutionary changes in genomics. HLA testing using NGS provides both high-throughput and high-resolution capabilities as compared with PCR-based techniques. To date, several high-throughput HLA-typing methods using NGS have been developed [34-36]. It will be more practical for a new established registry to adopt NGS-based typing, and perhaps more cost effective to outsource HLA typing to reference laboratories to secure better pricing and accurate standardized testing. Several commercial laboratories are available and offer competitive prices. The method of sample collection for HLA typing (blood, finger stick, buccal swab, etc.) can have an impact on the amount of DNA recovered for testing and as such affect the failure rate of the test so that backup sampling is recommended.

5. Software: information technology (IT) is necessary to run donor searches, to analyze HLA-haplotype frequencies and to predict the chances of finding a donor for each patient, who usually desperately needs a transplant in the shortest possible timeframe. Historically, large international registries developed their own software with their internal IT staff and/or external software companies and some may have used blood bank software as their starting point. These in-house built programs are typically complex and tightly tailored to the local needs. They are not available commercially and thus not available for emerging registries. Building an in-house program needs a lot of effort, 
Fig. 5 Probability to find a $10 / 10,9 / 10$, and $8 / 10$ match in Saudi Arabia

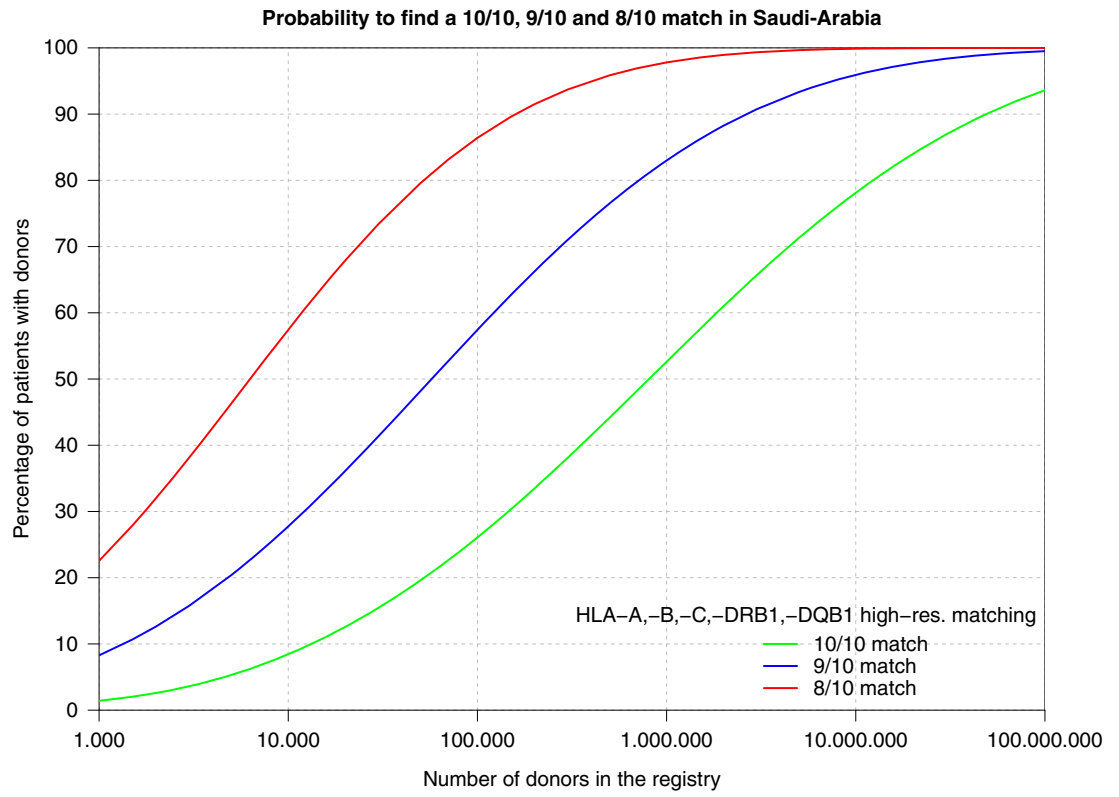

expertize, time, and expenses. This is particularly challenging for small and medium-sized emerging registries. Few commercial software packages for donor registries are now available in the market. Partnering with an established registry that has already developed an IT system is another way to acquire a software. Each of these models (home grown, commercial, partnership) has advantages and disadvantages (Table 1). The planning and preparation phase is the most critical phase. Ample time and a comprehensive team should be allocated to define the required functionality and ensure the security of the software. Once the scope of the system is decided (basic vs comprehensive), follow-up steps would include building a project team, studying the financial and quality requirements and then contracting with the suppliers. Table 2 summarizes the key steps for a successful planning phase. The ideal software should cover all key business processes of the registry daily work, including donor and patient data management, export to Search \& Match Service of WMDA (previously known as BMDW), international donor search processes, management of requests, finances, transplant records and donor/ patient follow-up. Table 3 outlines important elements for ideal registry software.

6. Emerging alternatives: outcomes after HCT from related haploidentical donors (siblings, children, and parents) have improved significantly over the past few years, with results approaching those of MUD and MSD transplants. The use of haploidentical HCT will extend the availability of allo-HCT to virtually all patients in need, as almost all patients will have an available haploidentical related donor. This advantage, in addition to the low cost and immediate availability, is particularly important for countries with no donor registries and where cost is prohibitive for acquiring unrelated donor cells from international registries or for establishing a national registry. All of these facts suggest that in countries with a relatively small population and some ethnic and genetic diversity, establishing an alternate donor registry and making matched grafts available for a very limited number of patients per year may not be cost effective unless the country's registry becomes part of an effective regional or international network for unrelated donors. Improvements in haploidentical HCT outcomes in the past decade, in particular using post-transplant cyclophosphamide, is making this alternative HCT modality preferred, over other alternative donors. Haploidentical family donor transplants are more affordable and readily available and therefore broadly used in many centers worldwide (Fig. 6), with a greater impact providing donors for patients in countries with limited resources. The availability of haploidentical HCT as alternative transplant modality has slowed the momentum toward establishing new regional registries or new cord blood banks.

7. Cord blood banks: Umbilical cord blood (UCB) banks provide an attractive, off the shelf solution for patients in need of an HCT. Recent studies showed comparable rates of acute graft-versus-host disease (GVHD) and significantly lower rates of chronic GVHD with cord blood transplant as compared to conventional matched donor transplant [3841]. Despite this, the emergence of haploidentical HCT led to steadily decline in the use of UCB since 2010 worldwide (Fig. 6) except for Japan (http://www.jdchct.or.jp/en/data/ slide/2017/). The disadvantages of using UCB are mainly the low yield of stem cells, resulting in delayed recovery, and the cost of graft acquisition from the international network of cord blood banks. 


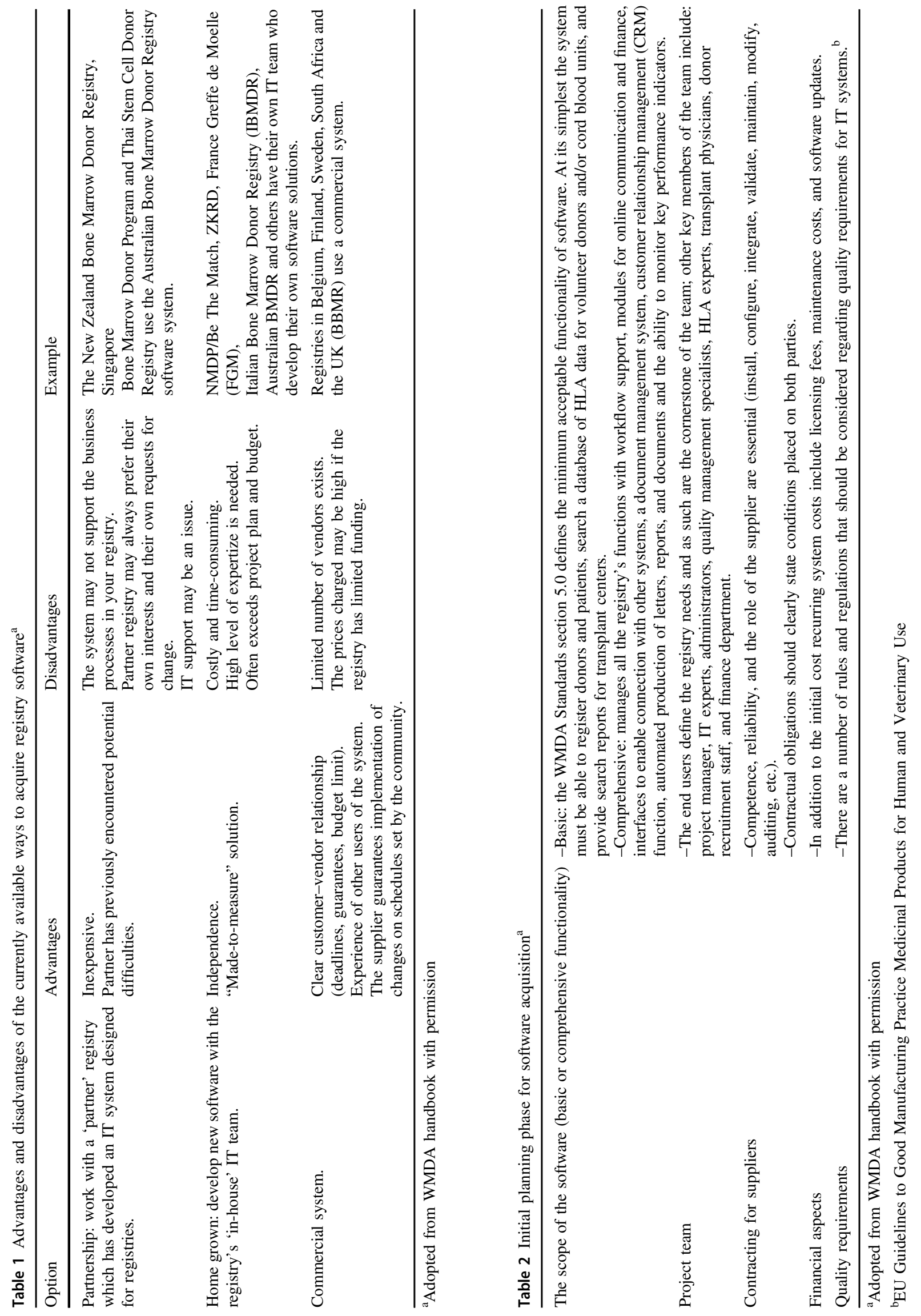




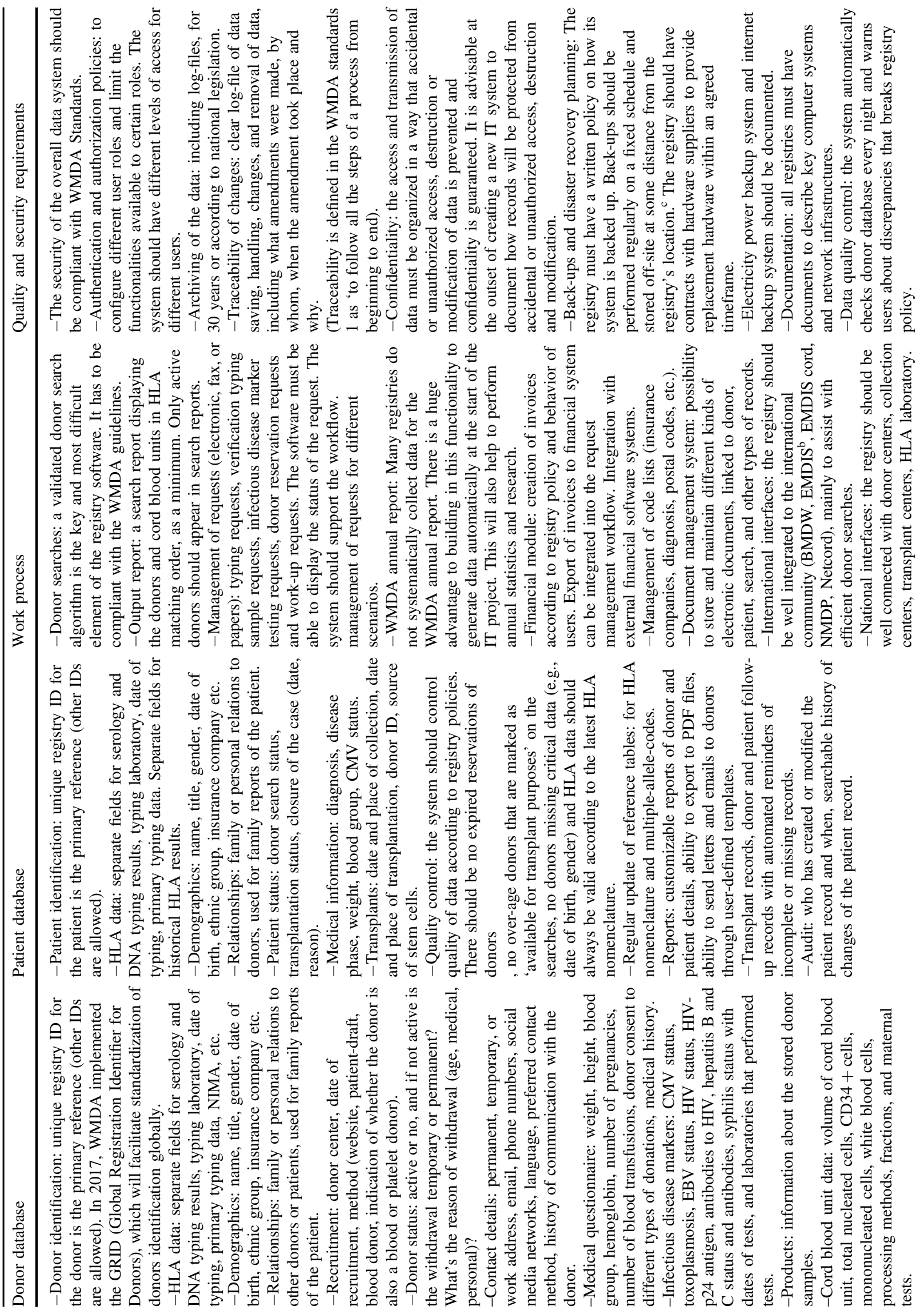




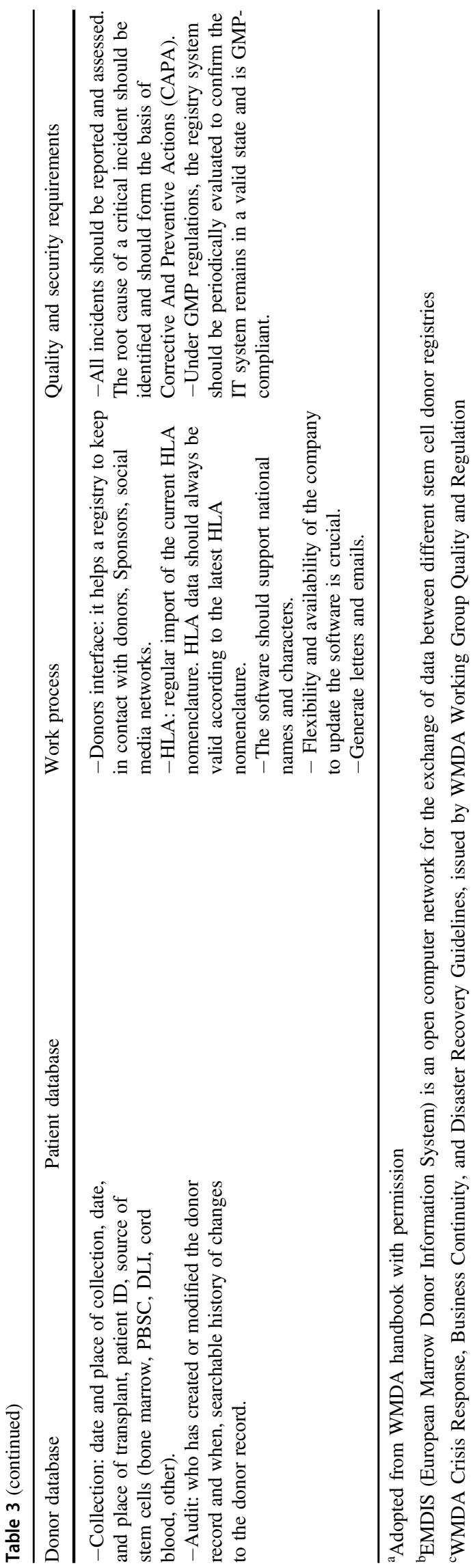

8. Utilization of artificial intelligence: artificial intelligence (AI) particularly with machine learning (ML) technology is revolutionizing the field of HCT in the selection of donors, and predicting outcomes after allo-HCT and even in GVHD [42-44]. The use of AI for donor-recipient pair matching in unrelated donor registries has been evaluated by multiple investigators and some have proven to increase accuracy of predictions for matching as well as for outcomes [45-47]. Although ML is perceived by some providers as a costly product, in fact, abundant data exist on predictions on how ML will reduce both costs and staffing along with improving clinical outcomes. As developing the ML modeling (especially via neural networks) for databases is done in collaboration with AI software engineers, a large number of startup companies exist that can help in developing algorithmic approaches for both active data management and for donor selection. Some of the developing countries adopting AI technology in healthcare include Morocco, Cameroon and South Africa (by integrating SOPHiA artificial intelligence for clinical genomics), and Rwanda (world's first national drone delivery network for delivery of blood to remote areas for transfusion). Thus, early adoption of AI in establishing databases is both feasible and recommended.

\section{Conclusion}

Although there has been a significant increase in the use of haploidentical related donors and unrelated cord blood (especially in Japan) as the stem cell source, the role of HCT from unrelated donors is well established. Establishing a functional and sustainable donor registry in a constantly evolving world is challenging, especially in the setting of limited resources and competition from emerging alternatives. Some existing registries are neither efficient nor able to provide suitable donors. Different causes of inefficiency exist, and all converge on the fact that resources may not be appropriately directed leading to poor performance and low yield of suitable donors. Analyzing the various steps in the process of recruitment, testing, retention until requested for donation may help in preventing donor attrition and thus increase the chance of building a successful registry. Educating the public may result in committed donors with low attrition rate, having a smart and easy-to-update software especially utilizing artificial intelligence algorithms, will ensure new HLA types are recorded and new search algorithms are built. Development of registries with widespread certified donation facilities will ease up the donation process. All of these are essential components for a functional registry. However, what remains both crucial and critical is the decision to build a registry or not, and that decision depends on the 

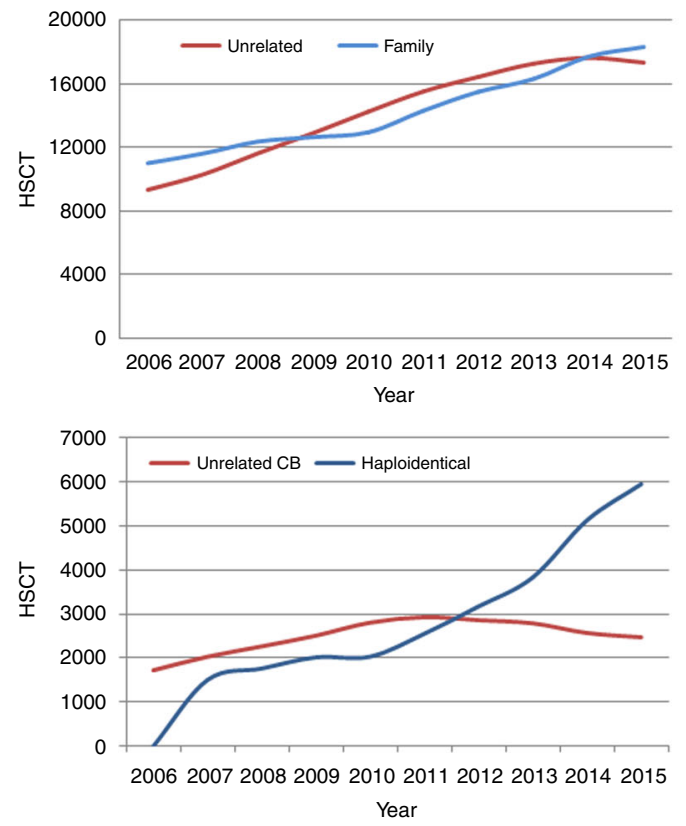

Fig. 6 Changes in donor choice 2006-2015

needs of the target population and the accessibility to alternative therapeutic options.

\section{Compliance with ethical standards}

Conflict of interest The authors declare that they have no conflict of interest.

Publisher's note: Springer Nature remains neutral with regard to jurisdictional claims in published maps and institutional affiliations.

Open Access This article is licensed under a Creative Commons Attribution 4.0 International License, which permits use, sharing, adaptation, distribution and reproduction in any medium or format, as long as you give appropriate credit to the original author(s) and the source, provide a link to the Creative Commons license, and indicate if changes were made. The images or other third party material in this article are included in the article's Creative Commons license, unless indicated otherwise in a credit line to the material. If material is not included in the article's Creative Commons license and your intended use is not permitted by statutory regulation or exceeds the permitted use, you will need to obtain permission directly from the copyright holder. To view a copy of this license, visit http://creativecommons. org/licenses/by/4.0/.

\section{References}

1. Rosenmayr A, Pointner-Prager M, Mitterschiffthaler A, Bozic L, Pelzmann B, Tuchler H, et al. What are a patient's current chances of finding a matched unrelated donor? Twenty years' central search experience in a small country. Bone Marrow Transplant. 2012;47:172-80.

2. Thomas ED, Lochte HL Jr, Lu WC, Ferrebee JW. Intravenous infusion of bone marrow in patients receiving radiation and chemotherapy. New Engl J Med. 1957;257:491-6.
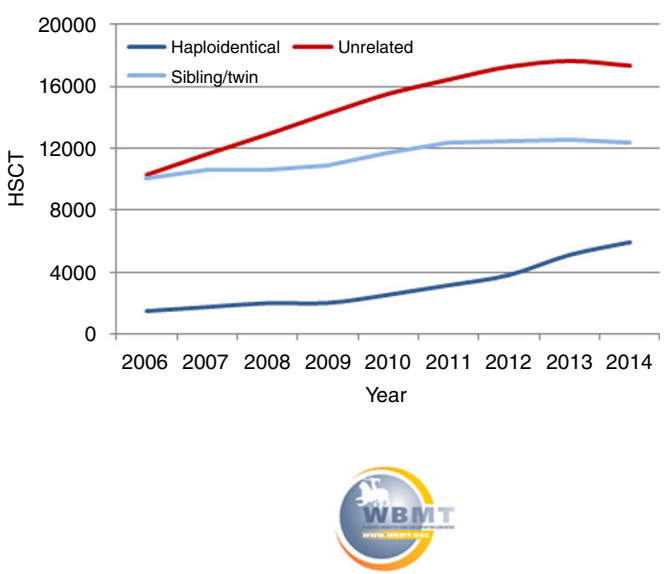

WBMT global survey 2006-2015

changes in donor choice preliminary data september 2018

3. Thomas ED. Bone marrow transplantation-past, present and future. Scand J Immunol. 1994;39:340-5.

4. Horowitz SD, Bach FH, Groshong T, Hong R, Yunis EJ. Treatment of severe combined immunodeficiency with bone-marrow from an unrelated, mixed-leucocyte-culture-nonreactive donor. Lancet. 1975;306:431-3.

5. Cleaver SA. The Anthony Nolan Research Centre. Bone Marrow Transplant. 1992;11:38-40.

6. Ruiz TM, Costa S, Ribas F, Luz PR, Lima SS, Graca. et al. Human leukocyte antigen allelic groups and haplotypes in a Brazilian sample of volunteer donors for bone marrow transplant in Curitiba, Parana, Brazil. Transplant Proc. 2005;37:2293-96.

7. Li XF, Zhang X, Chen Y, Zhang KL, Liu XJ, Li JP. An analysis of HLA-A, -B, and -DRB1 allele and haplotype frequencies of 21,918 residents living in Liaoning, China. PLoS ONE. 2014;9: e93082.

8. Eberhard H-P, Schmidt AH, Mytilineos J, Fleischhauer K, Muller CR. Common and well-documented HLA alleles of German stem cell donors by haplotype frequency estimation. HLA. 2018; 92:206-14.

9. Salminen E, Izewska J, Andreo P. IAEA's role in the global management of cancer-focus on upgrading radiotherapy services. Acta Oncol (Madr). 2005;44:816-24.

10. Rastogi T, Hildesheim A, Sinha R. Opportunities for cancer epidemiology in developing countries. Nat Rev Cancer. 2004; 4:909-17.

11. Torre LA, Bray F, Siegel RL, Ferlay J, Lortet-Tieulent J, Jemal A. Global cancer statistics. CA Cancer J Clin. 2012;65:87-108.

12. McGuire S. World cancer report. Geneva, Switzerland: World Health Organization, international agency for research on cancer, WHO Press, 2015. Oxford University Press; 2014.

13. Kanavos $P$. The rising burden of cancer in the developing world. Ann Oncol. 2006;17:viii15-viii23.

14. Roberts L. 9 Billion? Science. 2011;333:540-43.

15. Gratwohl A, Passweg J, Baldomero H, Horisberger B, UrbanoIspizua A. Economics, health care systems and utilization of haematopoietic stem cell transplants in Europe. Br J Haematol. 2002;117:451-68. 
16. Horowitz MM. Uses and growth of hematopoietic cell transplantation. Thomas' Hematopoietic Cell Transplantation: Stem Cell Transplantation, 4th edn, 2004;15-21.

17. Gratwohl A, Baldomero H, Gratwohl M, Aljurf MD, Bouzas LF, Horowitz M, et al. Quantitative and qualitative differences in use and trends of hematopoietic stem cell transplantation: a Global Observational Study. Haematologica. 2013;98:1282-90.

18. Dedhia L, Parekh S. Challenges faced by bone marrow registries in India. Indian Journal of Transplantation. 2014;8:80-3.

19. Maiers M, Halagan M, Joshi S, Ballal HS, Jagannatthan L, Damodar S, et al. HLA match likelihoods for Indian patients seeking unrelated donor transplantation grafts: a population-based study. Lancet Haematol. 2014;1:e57-e63.

20. Switzer GE, Bruce JG, Myaskovsky L, DiMartini A, Shellmer D, Confer DL, et al. Race and ethnicity in decisions about unrelated hematopoietic stem cell donation. Blood. 2013;121:1469-76.

21. Robinson J, Halliwell JA, McWilliam H, Lopez R, Parham P, Marsh SG. The IMGT/HLA database. Nucleic Acids Res. 2013;41 (Database issue):D1222-7.

22. Probst CM, Bompeixe EP, Pereira NF, De O Dalalio MM, Visentainer JEL, et al. HLA polymorphism and evaluation of European, African, and Amerindian contribution to the white and mulatto populations from Parana, Brazil. Hum Biol. 2000;72:597-617.

23. Monte SJHd, Moita Neto JM, Rampim GF, Shulzhenko N, Morgun A, Gerbase-DeLima M. HLA polymorphism in a racially admixed sample of the population of Teresina, Piaui. Rev Assoc Med Bras. 2004;50:422-6.

24. Jangi S. Problems of creating bone marrow donor registries in emerging economies. BMJ. 2013;346:f2976.

25. Al-Awwami M, Aljurf M, Al-Humidan H, El-Solh H, Almeshari $\mathrm{K}, \mathrm{Al}$-Seraihy A, et al. 85-P: HLA haplotype frequencies in saudi arabia for design of a saudi stem-cell registry. Hum Immunol. 2012;73:106.

26. Saito H, Ito M, Kato S, Kodera $Y$, Okamoto S, Taniguchi S, et al. The Japan Marrow Donor Program, 25 years of experience in achieving 20,000 bone marrow transplantations: organization structure, activity, and financial basis. Bone Marrow Transplant. 2018;53:609.

27. Eberhard HP, Madbouly AS, Gourraud PA, Balere ML, Feldmann $\mathrm{U}$, Gragert L, et al. Comparative validation of computer programs for haplotype frequency estimation from donor registry data. Tissue Antigens. 2013;82:93-105.

28. Mullis KB, Faloona FA. Specific synthesis of DNA in vitro via a polymerase-catalyzed chain reaction. Methods Enzymol. 1987; 155:335-50.

29. Zetterquist H, Olerup O. Identification of the HLA-DRB1*-04,DRB $1 *-07$, and-DRB $1 *-09$ alleles by PCR amplification with sequence-specific primers (PCR-SSP) in $2 \mathrm{~h}$. Hum Immunol. 1992;34:64-74

30. Lo YMD, Patel P, Mehal WZ, Fleming KA, Bell JI, Wainscoat JS. Analysis of complex genetic systems by ARMS-SSCP: application to HLA genotyping. Nucleic Acids Res. 1992;20:1005-9.

31. Petersdorf EW, Smith AG, Haase AM, Martin PJ, Hansen JA. Polymorphism of HLA-DRw52-associated DRB1 genes as defined by sequenceâ-specific oligonucleotide probe hybridization and sequencing. Tissue Antigens. 1991;38:169-77.

32. Santamaria P, Lindstrom AL, Boyce-Jacino MT, Myster SH, Barbosa JJ, Faras AJ, et al. HLA class I sequence-based typing. Hum Immunol. 1993;37:39-50.
33. Jiang B, Li Y, Wu H, He X, Li C, Li L, et al. Application of HLADRB1 genotyping by oligonucleotide micro-array technology in forensic medicine. Forensic Sci Int. 2006;162:66-73.

34. Gabriel C, Danzer M, Hackl C, Kopal G, Hufnagl P, Hofer K, et al. Rapid high-throughput human leukocyte antigen typing by massively parallel pyrosequencing for high-resolution allele identification. Hum Immunol. 2009;70:960-4.

35. Bentley G, Higuchi R, Hoglund B, Goodridge D, Sayer D, Trachtenberg EA, et al. High-resolution, high-throughput HLA genotyping by next-generation sequencing. Tissue Antigens. 2009;74:393-403

36. Erlich RL, Jia X, Anderson S, Banks E, Gao X, Carrington M, et al. Next-generation sequencing for HLA typing of class I loci. BMC Genomics. 2011;12:42.

37. Zhu B-f, Yang G, Shen C-m, Qin H-x, Liu S-z, Deng Y-j, et al. Distributions of HLA-A and-B alleles and haplotypes in the Yi ethnic minority of Yunnan, China: relationship to other populations. J Zhejiang Univ Sci B.2010;11:127-35.

38. Chen Y-B, Wang T, Hemmer MT, Brady C, Couriel DR, Alousi A, et al. GvHD after umbilical cord blood transplantation for acute leukemia: an analysis of risk factors and effect on outcomes. Bone Marrow Transplant. 2017;52:400.

39. Anasetti C, Logan BR, Lee SJ, Waller EK, Weisdorf DJ, Wingard JR, et al. Peripheral-blood stem cells versus bone marrow from unrelated donors. N Engl J Med. 2012;367:1487-96.

40. Brunstein CG, Eapen M, Ahn KW, Appelbaum FR, Ballen KK, Champlin RE, et al. Reduced intensity conditioning transplantation in acute leukemia: the effect of source of unrelated donor stem cells on outcomes. Blood. 2012;119:5591-98.

41. Brunstein CG, Gutman JA, Weisdorf DJ, Woolfrey AE, DeFor TE, Gooley TA, et al. Allogeneic hematopoietic cell transplantation for hematological malignancy: relative risks and benefits of double umbilical cord blood. Blood. 2010;116:4693-9.

42. Shouval R, Bonifazi F, Fein J, Boschini C, Oldani E, Labopin M, et al. Validation of the acute leukemia-EBMT score for prediction of mortality following allogeneic stem cell transplantation in a multi-center GITMO cohort. Am J Hematol. 2017;92:429-34.

43. Shouval R, Labopin M, Bondi O, Mishan-Shamay H, Ciceri F, Esteve J, et al. Prediction of allogeneic hematopoietic stem-cell transplantation mortality 100 days after transplantation using a machine learning algorithm: a European Group for Blood and Marrow Transplantation Acute Leukemia Working Party retrospective data mining study. J Clin Oncol. 2015;33:3144-52.

44. Li C-C, Ko B-S, Wang Y-F, Li J-L, Weng P-F, Hou H-A, et al. An artificial intelligence approach for predicting allogeneic hematopoietic stem cell transplantation outcome by detecting pretransplant minimal residual disease in acute myeloid leukemia using flow cytometry data. Blood. 2017;130:3980.

45. Buturovic L, Shelton J, Spellman SR, Wang T, Friedman L, Loftus D, et al. Evaluation of a machine learning-based prognostic model for unrelated hematopoietic cell transplantation donor selection. Biol Blood Marrow Transplant. 2018;24:1299-06.

46. Sarkar C, Srivastava J. Impact of density of lab data in ehr for prediction of potentially preventable events. Healthcare Informatics (ICHI), 2013 IEEE International Conference on: IEEE, 529-34.

47. Sivasankaran A, Cherkassky V, Albrecht M, Williams E, Maiers M. Donor Selection for Hematopoietic Stem Cell Transplant Using Cost-Sensitive SVM. Machine Learning and Applications (ICMLA), 2015 IEEE 14th International Conference on: IEEE, 831-6. 